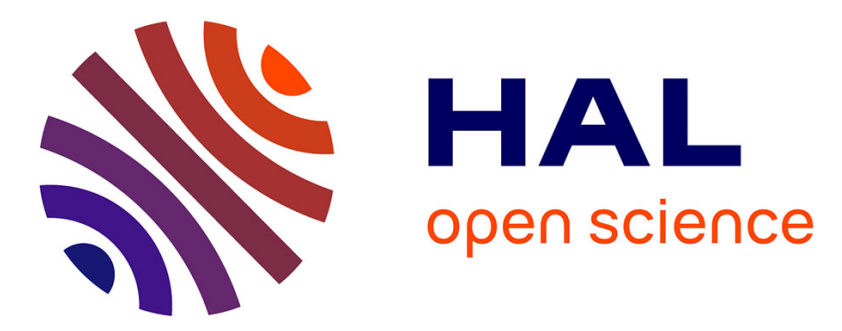

\title{
A 15N-Poor Isotopic Composition for the Solar System As Shown by Genesis Solar Wind Samples
}

\author{
B Marty, M Chaussidon, R. C. Wiens, A.J.G. Jurewicz, D. S. Burnett
}

\section{To cite this version:}

B Marty, M Chaussidon, R. C. Wiens, A.J.G. Jurewicz, D. S. Burnett. A 15N-Poor Isotopic Composition for the Solar System As Shown by Genesis Solar Wind Samples. Science, 2011, 10.1126/science.1204656 . hal-01346370

\author{
HAL Id: hal-01346370 \\ https://hal.science/hal-01346370
}

Submitted on 22 Dec 2020

HAL is a multi-disciplinary open access archive for the deposit and dissemination of scientific research documents, whether they are published or not. The documents may come from teaching and research institutions in France or abroad, or from public or private research centers.
L'archive ouverte pluridisciplinaire HAL, est destinée au dépôt et à la diffusion de documents scientifiques de niveau recherche, publiés ou non, émanant des établissements d'enseignement et de recherche français ou étrangers, des laboratoires publics ou privés. 


\title{
A ${ }^{15} \mathrm{~N}$-Poor Isotopic Composition for the Solar System As Shown by Genesis Solar Wind Samples
}

\author{
B. Marty, ${ }^{1 *}$ M. Chaussidon, ${ }^{1}$ R. C. Wiens, ${ }^{2}$ A. J. G. Jurewicz, ${ }^{3}$ D. S. Burnett ${ }^{4}$
}

The Genesis mission sampled solar wind ions to document the elemental and isotopic compositions of the Sun and, by inference, of the protosolar nebula. Nitrogen was a key target element because the extent and origin of its isotopic variations in solar system materials remain unknown. Isotopic analysis of a Genesis Solar Wind Concentrator target material shows that implanted solar wind nitrogen has a ${ }^{15} \mathrm{~N} /{ }^{14} \mathrm{~N}$ ratio of $2.18 \pm 0.02 \times 10^{-3}$ (that is, $\approx 40 \%$ poorer in ${ }^{15} \mathrm{~N}$ relative to terrestrial atmosphere). The ${ }^{15} \mathrm{~N} /{ }^{14} \mathrm{~N}$ ratio of the protosolar nebula was $2.27 \pm 0.03 \times 10^{-3}$, which is the lowest ${ }^{15} \mathrm{~N} /{ }^{14} \mathrm{~N}$ ratio known for solar system objects. This result demonstrates the extreme nitrogen isotopic heterogeneity of the nascent solar system and accounts for the ${ }^{15} \mathrm{~N}$-depleted components observed in solar system reservoirs.

$\mathrm{M}$ atter in the solar system is, in general, very well homogenized with respect to its isotopes, which is probably a result of efficient stirring in the highly turbulent nascent solar system. However, some of the light elements - those that were mostly present in the gaseous form, such as hydrogen $\left(\mathrm{H}_{2}\right)$, nitrogen $\left(\mathrm{N}_{2}\right)$, and oxygen $\left(\mathrm{CO}, \mathrm{H}_{2} \mathrm{O}\right)$ - present large, sometimes extreme, variations of their isotopic ratios (that is, $\mathrm{D} / \mathrm{H},{ }^{15} \mathrm{~N} /{ }^{14} \mathrm{~N}$, and ${ }^{17,18} \mathrm{O} /{ }^{16} \mathrm{O}$, respectively) among different solar system objects and reservoirs $(1-3)$. The cause of such variations (whether resulting from processes internal to the solar system or inherited from a presolar history) remains unclear, in part because the initial isotopic compositions of these elements in the protosolar gas are not known. To unravel this problem, the Genesis mission sampled solar wind (SW) ions in various target materials during 27 months at Lagrangian point L1 (4). SW ions give access to the composition of the Sun and, therefore, of the protosolar nebula (PSN) (5).

Nitrogen, the fifth most abundant element in the Sun, is particularly intriguing because its isotopic composition shows variations up to a factor of $\approx 6$ in solar system objects (excluding presolar grains), either at a microscopic scale or at the planetary scale $(2,6-9)$. Over the past few decades, numerous attempts have been made to determine the N isotopic composition of the Sun through the analysis of solar ions implanted in lunar soils; however, both ${ }^{15} \mathrm{~N}$-rich and ${ }^{15} \mathrm{~N}$-poor components were found on minerals from lunar soils $(8,9)$. These variations were first thought to represent a secular change of the nitrogen isotopic composition of the SW (9), but no known solar process could be invoked to produce these

${ }^{1}$ Centre de Recherches Pétrographiques et Géochimiques (CRPG), Nancy Université, BP 20, 54501 Vandoeuvre-lès-Nancy Cedex, France. ${ }^{2}$ Los Alamos National Laboratory, Los Alamos, NM 87545, USA. ${ }^{3}$ School of Earth and Space Exploration, Arizona State University, P.O. Box 871404, Tempe, AZ 85287-1404, USA. ${ }^{4}$ Department of Geological and Planetary Sciences, California Institute of Technology, Pasadena, CA 91125, USA.

${ }^{*}$ To whom correspondence should be addressed. E-mail: bmarty@crpg.cnrs-nancy.fr

variations, and mixing between solar and planetary $\mathrm{N}$ was later advocated $(7,10)$. More recently, ion-probe depth profiling of single lunar grains demonstrated that at a depth of $\approx 50 \mathrm{~nm}$, solar $\mathrm{H}$ (D-free) was associated with ${ }^{15} \mathrm{~N}$-poor N (e.g., depleted by at least $\approx 24 \%$ relative to terrestrial) and, thus, presumably of solar origin (6).

Ion-probe analysis of Genesis Concentrator silicon carbide target. We report here the precise isotopic analysis of SW N collected by implantation into a silicon carbide ( $\mathrm{SiC}$ ) quadrant of the target of the Genesis Solar Wind Concentrator, an electrostatic mirror (11) that increased the fluence of some SW elements by a factor up to $\sim 50(12,13)$. We analyzed along a traverse of the quadrant by secondary ion mass spectrometry using the Cameca 1280HR2 instrument recently installed at CRPG Nancy, France (14). This instrument has improved transfer optics and stability of primary and secondary beams that permits very-high-mass $(M)$ resolution (up to $M / \Delta M \approx 30,000)$ and high-precision isotope ratio measurements in multicollection mode. The $\mathrm{SiC}$ quadrant was sputtered using a $10-\mathrm{kV} \mathrm{Cs}^{+}$primary beam, and the resulting secondary ${ }^{12} \mathrm{C}^{14} \mathrm{~N}^{-}$ and ${ }^{12} \mathrm{C}^{15} \mathrm{~N}^{-}$ions were accelerated at $-10 \mathrm{kV}$ (total impact energy of $20 \mathrm{kV}$ ) and analyzed in multicollection electron multiplier mode at a mass resolution of $\approx 8000$, so that all potential isobaric interferences were resolved (14). ${ }^{29} \mathrm{Si}^{-}$ions were counted simultaneously to monitor the stability of the secondary beam with time (in a given depth profile), as well as to provide a way to normalize $\mathrm{N}$ isotope counts between different runs. Before analysis, four areas of 100 by $100 \mu \mathrm{m}$ were cleaned of surface contamination using a low-energy ion beam (14). In each of the four cleaned areas, 6 to 10 measurements were taken by depth profiling at different locations $(\approx 10-\mu \mathrm{m}$ diameter each). Procedural blanks were estimated by analyzing for $\mathrm{N}$ isotopes flight-spare $\mathrm{SiC}$ target material (kept on Earth) using the same analytical conditions and were found to be negligible $(<1 \%)$ for most analyses (Fig. 1). The implantation depths and fluences of SW nitrogen ions were estimated from the analysis of SiC implanted with ${ }^{15} \mathrm{~N}$ ions at known energy and fluence (14). Ion-probe instrumental mass discrimination was determined to be $-29.5 \pm$ 8.6 per mil (\%) by analyzing an $\mathrm{SiC}$ standard under the same conditions and comparing those data with the results previously obtained by laser ablation-static mass spectrometry (14).

Both ${ }^{14} \mathrm{~N}$ and ${ }^{15} \mathrm{~N}$ data define simple bellshaped distributions as a function of depth that peak $\sim 80 \mathrm{~nm}$ below the target's surface (Fig. 1), as expected for SW implantation at energies imposed by SW ion velocities and the Concentrator's ion acceleration (14). The measured ${ }^{15} \mathrm{~N} /{ }^{14} \mathrm{~N}$ ratio must be corrected for the instrumental mass fractionation (IMF) of the Genesis Concentrator, which varies as a function of position along its radius. This IMF was calibrated previously for the same $\mathrm{SiC}$ quadrant as a function of distance from the Concentrator's center using $\mathrm{Ne}$ (that is, by observing the deviation of the $\mathrm{Ne}$ isotopic composition extracted by laser ablation from known SW compositions) (15). From charge/mass considerations, the fractionation per mass unit of $\mathrm{N}$ (and O) isotopes should be comparable to that of $\mathrm{Ne}$ isotopes $(11,15)$; this relation allows the ${ }^{15} \mathrm{~N} /{ }^{14} \mathrm{~N}$ ratio to be corrected for the Concentrator's IMF on the basis of the Ne isotope fractionation. The $\mathrm{Ne}$ isotopic ratio measured in $\mathrm{SiC}$ at a distance of 18 to $20 \mathrm{~mm}$ from the Concentrator's center is not fractionated relative to the bulk SW neon isotopic composition $(15,16)$. Thus, we assume safely that the $\mathrm{N}$ isotopic composition of areas at 19-mm distance is that of the nonfractionated SW nitrogen. For other areas at 11 and $9 \mathrm{~mm}$ from the center, we use the $\mathrm{Ne}$ isotopic data to correct for Concentrator's isotopic fractionation (Table 1). However, these corrections are small—on the order of a few per mil (maximum: 19\%) - and mostly within stated errors. All detailed results, after corrections for the IMFs of both the Concentrator and the ion probe, are given in Table 1.

Isotopic composition of solar nitrogen. Our measurements yield a ${ }^{15} \mathrm{~N} /{ }^{14} \mathrm{~N}$ ratio for the $\mathrm{SW}$ of $2.178 \pm 0.024 \times 10^{-3}$ (95\% confidence level), corresponding to $\delta^{15} \mathrm{~N}=-407 \pm 7 \%$, where $\delta^{15} \mathrm{~N}=\left[\frac{\left(\frac{{ }^{15} \mathrm{~N}}{{ }^{14} \mathrm{~N}}\right)_{\text {sample }}}{\left(\frac{15 \mathrm{~N}}{{ }^{14} \mathrm{~N}}\right)_{\text {ATM }}}-1\right] \times 1000$ and ATM refers to the isotope composition of atmospheric nitrogen $\left(\left[{ }^{15} \mathrm{~N} /{ }^{14} \mathrm{~N}\right]_{\mathrm{ATM}}=3.676 \times 10^{-3}\right)$. By its high precision, this result definitely settles the debate on the $\mathrm{N}$ isotopic composition of SW (17-19): it is extremely ${ }^{15} \mathrm{~N}$-poor, as proposed in $(18,19)$. Such a ${ }^{15} \mathrm{~N}$-depleted component (the ${ }^{15} \mathrm{~N} /{ }^{14} \mathrm{~N}$ ratio not being precisely known) was previously suspected to exist in meteoritic matter $(2,20)$ and the jovian atmosphere (21), but it was not understood as representing the solar composition.

The Sun's bulk ${ }^{15} \mathrm{~N} /{ }^{14} \mathrm{~N}$ ratio can be obtained from our Genesis SW measurement after correction for isotopic fractionation taking place during acceleration of SW from the photosphere and, possibly, in the convective zone of the Sun. The effect of solar diffusive element settling plus radiative levitation (DESRL) (22) is estimated to 
result in $\approx 5$ to $9 \%$ per atomic mass unit (amu) depletion in ${ }^{15} \mathrm{~N}$ of the $\mathrm{SW}$ over 4.5 billion years (23). Isotopic fractionation during acceleration of the SW from the photosphere occurs for noble gases (24), but it is far less well understood or quantified when compared with elemental fractionation, which, to first order, is governed by the element's first ionization potential (FIP). The Coulomb drag model of Bodmer and Bochsler (25) considers the correlation of the isotopic fractionation with the $\mathrm{He} / \mathrm{H}$ elemental fractionation, assuming that the almost-factor-of-two fractionation in these elements between photosphere and SW is due to Coulomb drag alone and not to FIP fractionation. For nitrogen isotopes, the fractionation factor would be 1.041 . Independently, oxygen isotope data obtained for the same $\mathrm{SiC}$ quadrant (20) suggest a mass-dependent isotopic fractionation factor of 1.022 per amu. For oxygen, gravitational settling accounts for a fractionation of 1.003 over the Sun's lifetime (27) such that the effect of SW processing should be 1.019 per amu, whereas the Coulomb drag model predicts a higher fractionation factor of 1.026 per amu. We tentatively assign a SW fractionation factor of $1.041 / 1.026 \times 1.019=1.034( \pm 0.005)$ for $\mathrm{N}$ isotopes, in addition to the $1.007( \pm 0.002)$ fractionation factor due to DESRL. Thus, our estimate for the ${ }^{15} \mathrm{~N} /{ }^{14} \mathrm{~N}$ ratio of the bulk Sun, after correction for solar processing and propagation of all errors, is $2.268 \pm 0.028 \times 10^{-3}(95 \%$ confidence level; $\delta^{15} \mathrm{~N}=-383 \pm 8 \%$ ).

This corrected ${ }^{15} \mathrm{~N} /{ }^{14} \mathrm{~N}$ ratio is a proxy for that of the PSN. This ratio is much lower than that of the terrestrial atmosphere $\left(3.676 \times 10^{-3}\right)$, but it is identical to that measured in Jupiter's atmosphere $\left[{ }^{15} \mathrm{~N} /{ }^{14} \mathrm{~N}=2.3 \pm 0.3 \times 10^{-3}(21)\right]$ within the relatively large errors in the Jupiter ratio. Our solar ${ }^{15} \mathrm{~N} /{ }^{14} \mathrm{~N}$ is also very close to that $(2.36 \pm$ $0.04 \times 10^{-3}$ ) found in a grain of osbornite $(\mathrm{TiN})$ embedded in a calcium- and aluminum-rich inclusion (CAI) from the $\mathrm{CH} / \mathrm{CB}$ chondrite Isheyevo (28). The presence of TiN in a CAI is understood as reflecting high-temperature $(\approx 2000 \mathrm{~K})$ condensation from the PSN under reducing conditions. In detail, however, osbornite appears to be enriched in ${ }^{15} \mathrm{~N}$ by $42 \pm 22 \%$ relative to our PSN value. If negligible isotopic fractionation took place during high-temperature condensation, the reservoir in the accretion disk from which the osbornite condensed might have been slightly modified from the PSN composition, as, for example, in the case of oxygen isotopes in CAIs (29). The difference between our PSN value determined from present-day SW and the osbornite $\mathrm{N}$ isotopic composition cannot be due to contribution of nitrogen isotopes produced in the Sun over its lifetime. For instance, the ${ }^{15} \mathrm{~N} /{ }^{14} \mathrm{~N}$ ratio of the outer Sun could, in principle, be affected by leakage from the Sun's core in which ${ }^{14} \mathrm{~N}$ is produced by the carbon-nitrogen-oxygen cycle. However, both solar physics (30) and the absence of SW He isotope variation in lunar soils exposed at different epochs (31) indicate no contribution of matter from the solar core to the convective zone. Theoretically, nucleosynthesis of nitrogen isotopes in solar flares might also have changed the ${ }^{15} \mathrm{~N} /{ }^{14} \mathrm{~N}$ ratio of the outer Sun. However, the effect is predicted to be negligible in the case of spallation for $\mathrm{N}$, though it might be detectable for $\mathrm{Li}$ (32).

Because the PSN is the most ${ }^{15} \mathrm{~N}$-depleted, as well as the most gas-rich, reservoir in the solar system, we propose that the $\mathrm{N}$ isotope variations among solar system bodies result from variable mixing between a ${ }^{15} \mathrm{~N}$-poor gaseous component and solids rich in nitrogen-15. Observed $\mathrm{H}, \mathrm{N}$, and $\mathrm{O}$ isotopic variations are consistent with variable mixtures of a PSN component with components rich in heavy and rare isotopes $\left(\mathrm{D},{ }^{15} \mathrm{~N}\right.$, and ${ }^{17,18} \mathrm{O}$, respectively) (Fig. 2). Alternatively, these enrichments might have resulted from interactions between photons and matter (e.g., photochemistry, ion-molecule reactions) that took place before or during formation of the solar system (33-36). The existence of a common origin for these strong D-, ${ }^{15} \mathrm{~N}-,{ }^{17} \mathrm{O}$-, and ${ }^{18} \mathrm{O}$-enrichments is a key question.

Planetary implications. The agreement of the Sun's and Jupiter's outer atmosphere ${ }^{15} \mathrm{~N} /{ }^{14} \mathrm{~N}$ is of considerable importance, because Jupiter's atmosphere is enriched in $\mathrm{N} / \mathrm{H}$ (along with $\mathrm{Ar}, \mathrm{Kr}, \mathrm{Xe}$, $\mathrm{C}$, and S) by about a factor of 3 compared with the solar photospheric elemental ratios $(37,38)$. We assume that the $\mathrm{N}$ isotopic composition of Jupiter's atmosphere is representative of the whole planet. These enhancements are usually interpreted as indicating that Jupiter is a mixture of solar nebula gas (the source of $\mathrm{H}$ and $\mathrm{He}$ ) and outer solar system planetesimals [the source of the other, less volatile, elements (37)]. If this interpretation is correct, then only about one-fourth of the $\mathrm{N}$ in Jupiter is of nebula origin. Nevertheless, Jupiter has preserved
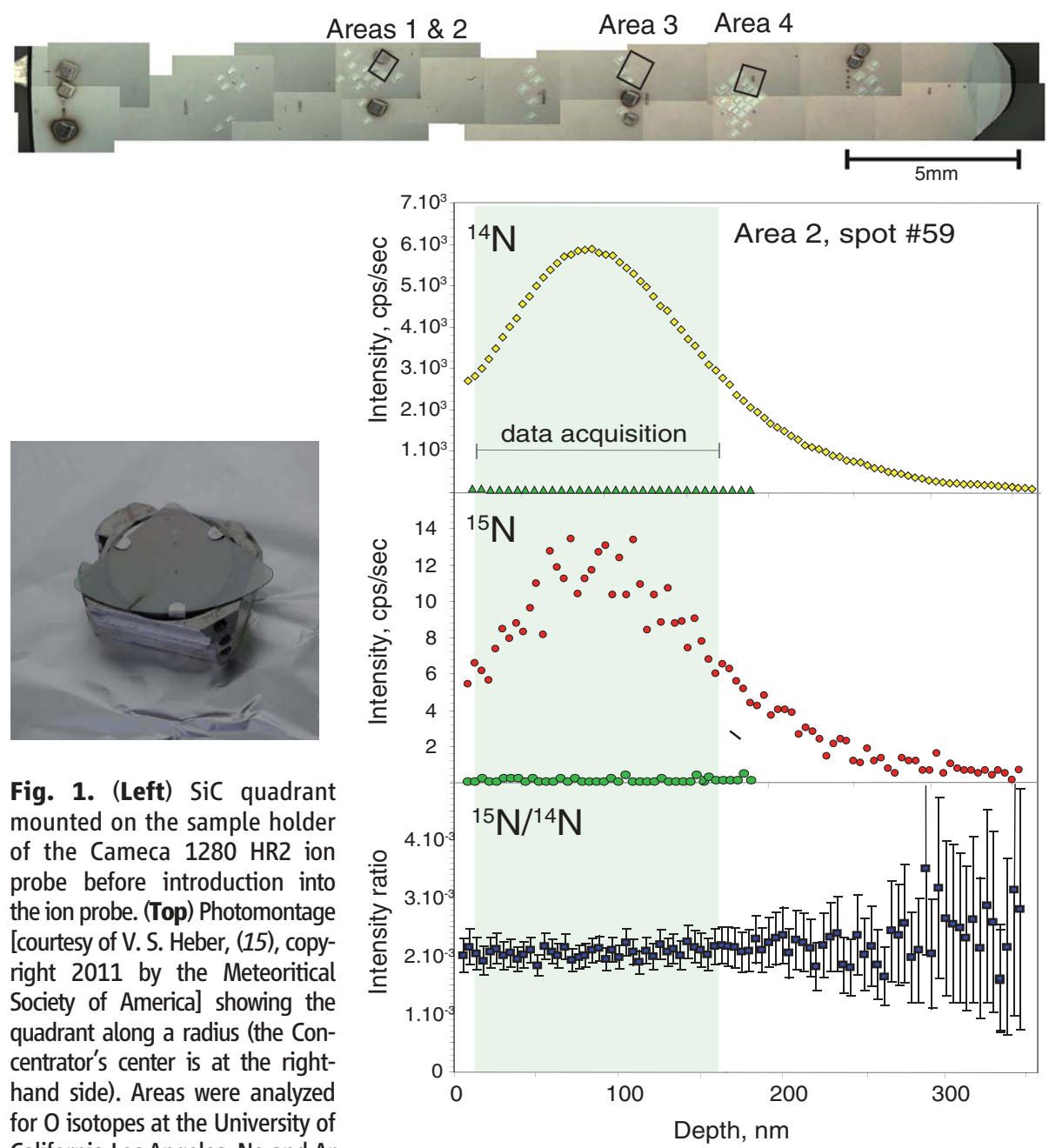

Fig. 1. (Left) $\mathrm{SiC}$ quadrant mounted on the sample holder of the Cameca 1280 HR2 ion probe before introduction into the ion probe. (Top) Photomontage [courtesy of V. S. Heber, (15), copyright 2011 by the Meteoritical Society of America] showing the quadrant along a radius (the Concentrator's center is at the righthand side). Areas were analyzed for $\mathrm{O}$ isotopes at the University of California Los Angeles, Ne and $\mathrm{Ar}$ isotopes at ETH Zurich, and N isotopes at CRPG Nancy (areas delineated by squares are those analyzed for $\mathrm{N}$ ). (Right) Example of evolution of the ${ }^{14} \mathrm{~N}$ (analyzed as ${ }^{12} \mathrm{C}^{14} \mathrm{~N}$ ) and ${ }^{15} \mathrm{~N}$ (analyzed as ${ }^{12} \mathrm{C}^{15} \mathrm{~N}$ ) intensities and of the ${ }^{15} \mathrm{~N} /{ }^{14} \mathrm{~N}$ intensity ratios as function of depth inside the $\mathrm{SiC}$ target (the target surface is at the left-hand side of the diagram). Green symbols (triangles and circles) represent data obtained for a blank SiC target identical to the flight target. The light green shaded area delineates data used for quantification of the SW N composition. These data were selected by removing the first five data points closest to the surface and by selecting data defining a Gaussian curve relative to the top of the bell-shaped distribution. Yellow diamonds, ${ }^{14} \mathrm{~N}$ as a function of depth; red circles, ${ }^{15} \mathrm{~N}$ as a function of depth; blue squares, ${ }^{15} \mathrm{~N} /{ }^{14} \mathrm{~N}$ ratios. cps, counts per second. Error bars were computed from counting statistics. 
the solar ${ }^{15} \mathrm{~N} /{ }^{14} \mathrm{~N}$ ratio, requiring that the $\mathrm{N}$ in the planetesimal contribution had a low ${ }^{15} \mathrm{~N} /{ }^{14} \mathrm{~N}$ ratio, with only very small contributions from the very high ${ }^{15} \mathrm{~N} /{ }^{14} \mathrm{~N}$ ratio observed in cometary $\mathrm{HCN}$ and $\mathrm{CN}$ (39) or even the more modest ${ }^{15} \mathrm{~N} /{ }^{14} \mathrm{~N}$ ratio enrichments measured in bulk inner solar system carbonaceous chondrite material. Thus, either the model for the origin of jovian volatiles is not correct, or the cometary $\mathrm{HCN}-\mathrm{CN}{ }^{15} \mathrm{~N} /{ }^{14} \mathrm{~N}$ may not be representative of outer solar system, possibly even cometary, matter.

The extremely ${ }^{15} \mathrm{~N}$-poor composition for the PSN provides the ${ }^{15} \mathrm{~N}$-depleted component required to account for the $\mathrm{N}$ isotope variations previously recognized in solar system objects (Fig. 2). Presolar phases, which show a range of ${ }^{15} \mathrm{~N} /{ }^{14} \mathrm{~N}$ ratios from $\sim 50$ to $\sim 20,000(40)$, are usually considered to be negligible to the solar system $\mathrm{N}$ budget. The average abundances in chondrites of presolar diamonds, $\mathrm{SiC}$, and graphite are $\sim 1000, \sim 10$ and $\sim 1$ parts per million (ppm), respectively (40), and their $\mathrm{N}$ contents (with the exception of $\mathrm{Si}_{3} \mathrm{~N}_{4}$ ) range from $\sim 500$ to $\sim 10,000$ ppm (41). Contrary to unequivocal presolar grains, the origin of meteoritic nanodiamonds is unclear because, although they can contain presolar xenon (42), their C isotopic composition is solar (43). The nanodiamond ${ }^{15} \mathrm{~N} /{ }^{14} \mathrm{~N}$ ratio $[2.40 \pm 0.03 \times$
$10^{-3}$ (43)] is similar to that of the PSN, which might also point to a solar origin. It is possible that most nanodiamonds formed in the solar system, with only a small fraction (those hosting isotopically anomalous $\mathrm{Xe}$ ) being inherited from other stellar systems. In detail, nanodiamonds, which comprise several populations, are enriched in ${ }^{15} \mathrm{~N}$ by $58 \pm 17 \%$ o relative to the PSN composition. Hence, they might have sampled regions of the disk enriched in ${ }^{15} \mathrm{~N}$ by addition of a minor, presumably nucleosynthetic, component, possibly the one hosting the anomalous Xe.

Our result also has implications for the origin of volatile elements in terrestrial planets. These elements have similar $\mathrm{N}$ and $\mathrm{H}$ isotopic compositions to those of the sources of some chondritic materials (Fig. 2). Mixing between a D-rich, ${ }^{15} \mathrm{~N}$-rich component, as observed in some comets with a solar reservoir (Fig. 2), cannot account for the relative homogeneity (ignoring factors of 1.5 or less) of $\mathrm{N}$ and $\mathrm{H}$ isotopic ratios of inner planets and meteorites. Instead, this homogeneity suggests relatively efficient stirring and mixing of at least three $(\mathrm{N}, \mathrm{H})$ components in the inner solar system.

Nitrogen isotopic variations in meteorites provide a new cosmochemical tracer for understanding chemical and thermodynamical heterogeneities during condensation, dust aggregation and coalescence, and parent-body processing. Variations of the bulk $\mathrm{N}$ isotopic compositions of meteorites (44-46) are now consistent with mixing between a ${ }^{15} \mathrm{~N}$-rich end-member, hosted by organics and dominating the carbonaceous chondrite inventory, and a ${ }^{15} \mathrm{~N}$-depleted component derived from the PSN, preferentially hosted by silicate and metal phases. Insoluble organic matter in meteorites can be extremely rich in ${ }^{15} \mathrm{~N}$ on a micron scale $(47,48)$ and was probably the source of the large ${ }^{15} \mathrm{~N}$ enrichments observed in $\mathrm{CR} / \mathrm{CB}$ meteorites $(49,50)$. The incorporation of PSN nitrogen could have taken place either during nebular condensation or by solution in molten silicates and could have been most efficient under reducing conditions imposed by the composition of the PSN. From the composition of the PSN and adopting canonical conditions for the inner solar system [pressure $P=10^{-3} \mathrm{~atm}$, temperature $T=1500 \mathrm{~K}$, $\log f_{\mathrm{O}_{2}} \approx-19$ (where $f_{\mathrm{O}_{2}}$ is the oxygen fugacity) (51)], $\sim 4$ to 100 ppm of solar $\mathrm{N}$ could have been dissolved from the PSN into a basaltic melt [the only composition for which the $\mathrm{N}$ solubility as a function of $\mathrm{fO}_{2}$ has been measured (52)], making a substantial fraction of meteoritic nitrogen (range: 1 to $1000 \mathrm{ppm} \mathrm{N}$ ). For the same $P-T$ conditions and at $\log f_{\mathrm{O}_{2}} \approx-20.3$ [for enstatite chondrite
Table 1. Results from the analysis of different areas along the Concentrator's SiC quadrant (SOM, figs. S5 to S8). (Top) For each area, 6 to 10 spots were analyzed, and 60 counting runs $\left({ }^{12} \mathrm{C}^{14} \mathrm{~N},{ }^{12} \mathrm{C}^{15} \mathrm{~N}\right.$, and $\left.{ }^{30} \mathrm{Si}\right)$ were made for each spot. Each spot value given here represents the average of the corresponding runs. The $95 \%$ confidence intervals $(\mathrm{Cls})$ for each spot are taken as the $2 \sigma / \sqrt{ }(n)$ values (where $n$ is the number of data points in the spot). The average values for each area have been weighted by the $95 \% \mathrm{Cls}$ of each spot. The $\mathrm{N}$ isotopic ratios can also be obtained by computing the ratios of the background-corrected sums of ${ }^{15} \mathrm{~N}$ and ${ }^{14} \mathrm{~N}$ counts, which gives the same values as above within 2 to $3 \%$, well within errors. (Bottom) The averages of each area have been corrected for the Concentrator's fractionation using the Ne isotopic ratios for the corresponding areas [Ne data from (15)], assuming similar isotopic fractionation per mass unit for $\mathrm{Ne}$ and $\mathrm{N}$ [see $(13,15)$ for justification]. The weighted average of all areas' data are given at the bottom right of the lower section of the table. These values are finally corrected for the instrumental mass fractionation in the ion probe (corr. IMF), determined from the analysis of standard SiC. ATM refers to the nitrogen isotopic composition of the terrestrial atmosphere.

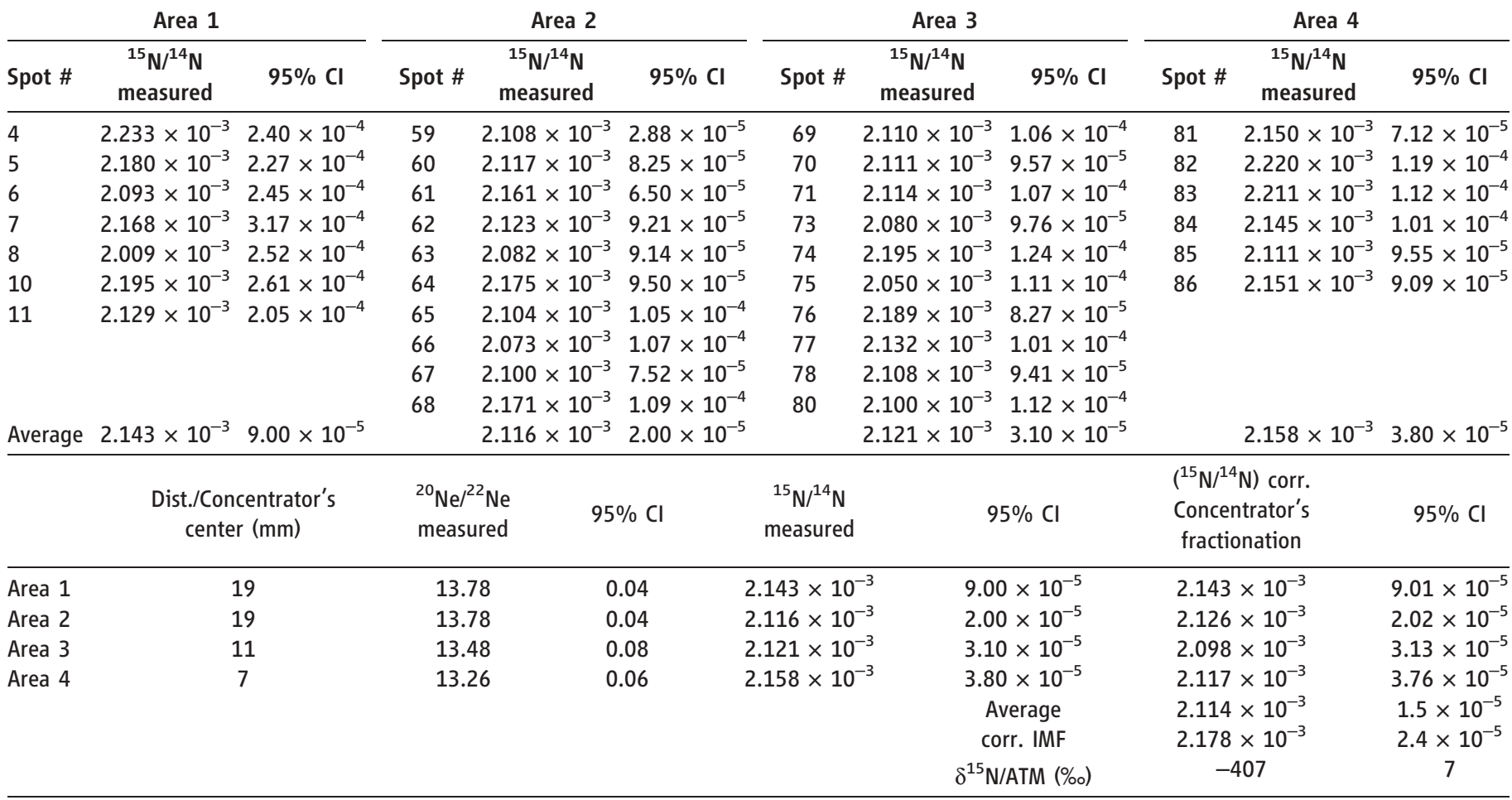


Fig. 2. Variations of the nitrogen isotopic composition as a function of the $\mathrm{D} / \mathrm{H}$ ratio (left), the oxygen isotopic composition [(right), expressed as $\Delta^{17} \mathrm{O}$, which is the distance from the mass-dependent terrestrial fractionation line equal to $0.52 \times$ $\left.\delta^{18} 0(1)\right]$. For the nitrogen versus oxygen isotopic compositions, two end members are considered: End-member 1 (EM1) is the cometary composition for $\mathrm{N}$ (39) and the isotope composition estimated for the aqueous component that altered carbonaceous chondrites (29); end-member 2 (EM2) is defined with the $\mathrm{N}$ isotope composition of the most ${ }^{15} \mathrm{~N}$-rich component

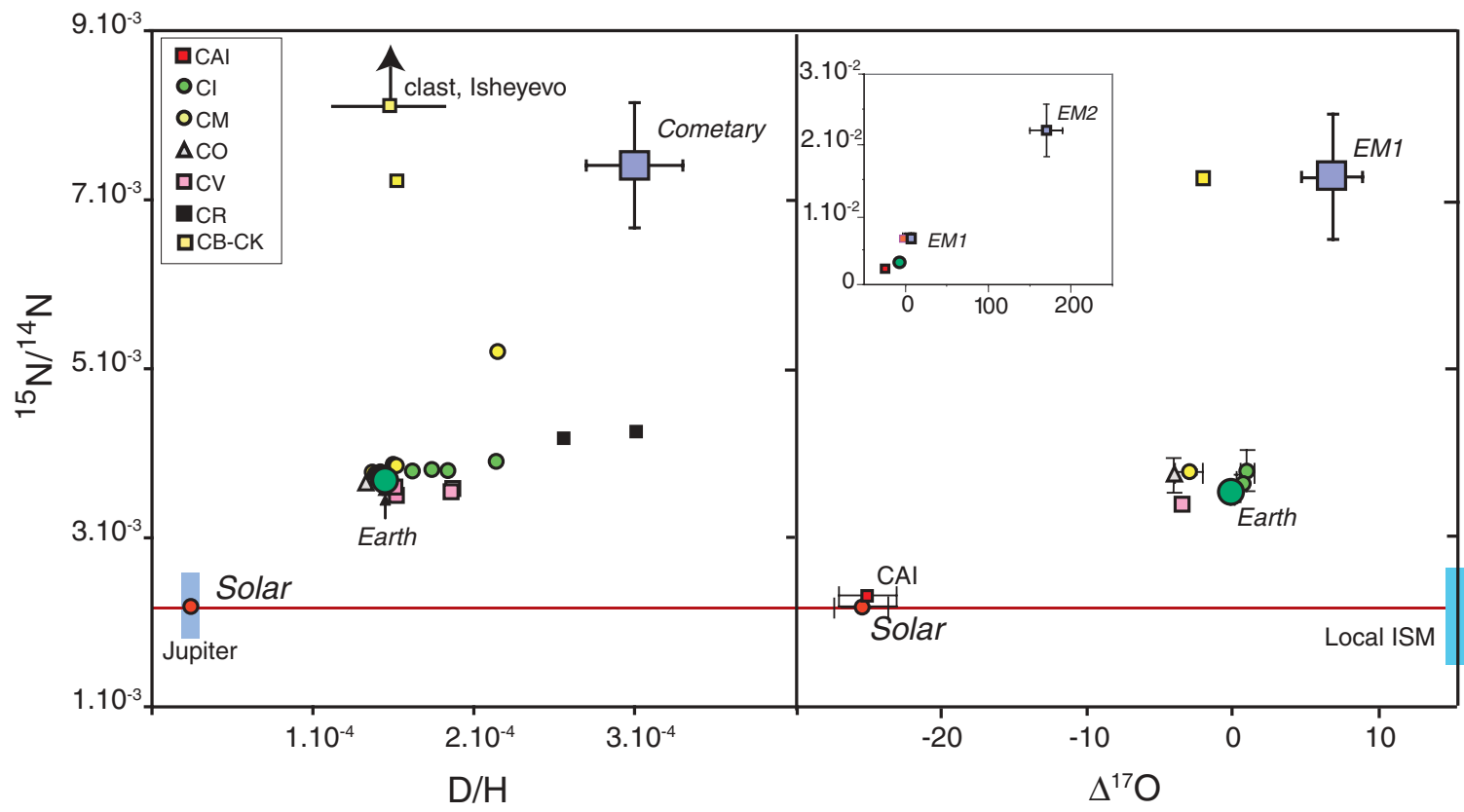

found in the Isheyevo $\mathrm{CH} / \mathrm{CB}$ chondrite (47) and with the matrix of the carbonaceous chondrite Acfer 094 which has the most extreme 0 isotope composition found in meteorites and is thought to be a remnant of early solar system water (53). (Inset) Same diagram with an expanded scale.

composition (51)], 230 ppm solar N would have been dissolved, which, by mixing with $~ 1000$-ppm organic $\mathrm{N}$ with $\delta^{15} \mathrm{~N} \approx+40 \%$ typical of nitrogen in $\mathrm{CI} / \mathrm{CM}$ carbonaceous chondrites (46), will yield a $\delta^{15} \mathrm{~N}$ value of $\sim-40 \%$, as observed in enstatite meteorites (46). Thus, the isotopes of nitrogen also have a great potential for understanding chondrite evolutionary processes (e.g., chondrule formation events) and the evolution of planetesimals in their early stage when they were partially molten.

\section{References and Notes}

1. R. N. Clayton, Space Sci. Rev. 106, 19 (2003)

2. J. F. Kerridge, Rev. Geophys. 31, 423 (1993).

3. J. Geiss, H. Reeves, Astron. Astrophys. 93, 189 (1981).

4. The Lagrangian point L1 of the Earth-Sun system is the point at which the orbital period of an object rotating around the Sun becomes exactly equal to Earth's orbital period, so that its location relative to both objects does not change with time.

5. D. S. Burnett et al., Space Sci. Rev. 105, 509 (2003).

6. K. Hashizume, M. Chaussidon, B. Marty, F. Robert, Science 290, 1142 (2000).

7. J. Geiss, P. Bochsler, Geochim. Cosmochim. Acta 46, 529 (1982).

8. R. H. Becker, R. N. Clayton, Proc. Lunar Sci. Conf. 6 , 2131 (1975)

9. J. F. Kerridge, Science 188, 162 (1975)

10. R. Wieler, F. Humbert, B. Marty, Earth Planet. Sci. Lett. 167, 47 (1999).

11. J. E. Nordholt et al., Space Sci. Rev. 105, 561 (2003).

12. R. C. Wiens et al., Space Sci. Rev. 105, 601 (2003).

13. V. S. Heber et al., Space Sci. Rev. 130, 309 (2007).

14. Materials and methods are available as supporting material on Science Online.

15. V. S. Heber et al., Meteorit. Planet. Sci. 46, 493 (2011).

16. A. Grimberg et al., Science 314, 1133 (2006).

17. R. O. Pepin, R. H. Becker, D. J. Schlutter, Lunar and Planetary Science Conference, \#2103 (2009).

18. B. Marty et al., Geochim. Cosmochim. Acta 74, 340 (2010).

19. A. P. Kallio et al., Lunar and Planetary Science Conference, \#2481 (2010).

20. C. C. Kung, R. N. Clayton, Earth Planet. Sci. Lett. 38, 421 (1978).

21. T. Owen, P. R. Mahaffy, H. B. Niemann, S. Atreya, M. Wong, Astrophys. J. 553, L77 (2001).
22. S. Turcotte, ]. Richer, G. Michaud, C. A. Iglesias, F. J. Rogers, Astrophys. J. 504, 539 (1998)

23. P. Bochsler, Rev. Geophys. 38, 247 (2000).

24. V. S. Heber et al., Lunar and Planetary Science Conference, \#1779 (2008).

25. P. Bodmer, P. Bochsler, Astron. Astrophys. 337, 921 (1998).

26. K. D. McKeegan et al., Science 332, 1528 (2011).

27. S. Turcotte, R. F. Wimmer-Schweingruber, J. Geophys. Res. 107, 11 (2002)

28. A. Meibom et al., Astrophys. J. 656, L33 (2007)

29. K. D. McKeegan, L. A. Leshin, in Stable Isotope Geochemistry (Mineralogical Society of America, Washington, DC, 2001), vol. 43, pp. 279-318.

30. J. N. Bahcall, M. C. Gonzalez-Garcia, C. Peña-Garay, Phys. Rev. Lett. 90, 131301 (2003).

31. V. S. Heber, H. Baur, R. Wieler, Astrophys. J. 597, 602 (2003).

32. M. Chaussidon, F. Robert, Nature 402, 270 (1999).

33. R. Terzieva, E. Herbst, Mon. Not. R. Astron. Soc. 317, 563 (2000).

34. R. N. Clayton, Nature 415, 860 (2002).

35. S. Chakraborty, M. Ahmed, T. L. Jackson, M. H. Thiemens, Science 321, 1328 (2008).

36. J. Aléon, Astrophys. J. 722, 1342 (2010)

37. T. Owen et al., Nature 402, 269 (1999).

38. F. W. Taylor et al., in Jupiter, T. D. F. Bagenal, W. MacKinnon, Eds. (Cambridge Univ. Press, Cambridge, 2004), pp. 60-78.

39. D. Bockelée-Morvan et al., Astrophys. J. 679, L49 (2008).

40. E. K. Zinner, in Treatise on Geochemistry, K. K. Turekian, H. D. Holland, A. M. Davis, Eds. (Elsevier, Oxford, 2004), vol. 1, pp. 17-39.

41. E. Zinner et al., Geochim. Cosmochim. Acta 71, 4786 (2007).

42. T. Ming, E. Anders, Geochim. Cosmochim. Acta 52, 1235 (1988).

43. S. S. Russell, J. W. Arden, C. T. Pillinger, Meteorit. Planet. Sci. 31, 343 (1996).

44. J. F. Kerridge, Geochim. Cosmochim. Acta 49, 1707 (1985).

45. C. A. Prombo, R. N. Clayton, Geochim. Cosmochim. Acta 57, 3749 (1993).

46. $\delta^{15} \mathrm{~N}$ values are: $+40 \%$ ofor $\mathrm{Cl} / \mathrm{CM}$ carbonaceous chondrites, close to $0 \%$ o for ordinary chondrites, $-30 \pm 10 \%$ o for enstatite chondrites, and -60 to $-80 \%$ 。 for the major iron meteorite families IAB, IIAB, IIIAB and IIICD $(20,44,45)$

47. G. Briani et al., Proc. Natl. Acad. Sci. U.S.A. 106, 10522 (2009)

48. L. Bonal et al., Geochim. Cosmochim. Acta 74, 6590 (2010).
49. C. A. Prombo, R. N. Clayton, Science 230, 935 (1985).

50. M. M. Grady, C. T. Pillinger, Earth Planet. Sci. Lett. 97, 29 (1990).

51. L. Grossman, ]. R. Beckett, A. V. Fedkin, S. B. Simon, F. J. Ciesla, in Oxygen in the Solar System, G. J. MacPherson, D. W. Mittlefehldt, ]. H. Jones, S. B. Simon, Eds. (Mineralogical Society of America, Chantilly, VA, 2008), vol. 68, pp. 93-140.

52. G. Libourel, B. Marty, F. Humbert, Geochim. Cosmochim. Acta 67, 4123 (2003).

53. N. Sakamoto et al., Science 317, 231 (2007); 10.1126/science.1142021.

Acknowledgments: Funding in the U.S. was provided by NASA through the Genesis Discovery Mission and through the Laboratory Analysis of Returned Samples program. The ultimate success of the mission would not have been possible without major engineering contributions from the Los Alamos National Laboratory (Genesis Concentrator), Jet Propulsion Laboratory (payload, mission operations, management), Lockheed Martin Aerospace (spacecraft and reentry capsule), and the Johnson Space Center (payload integration and curation). This study was funded in France by the Centre National d'Etudes Spatiales, the Centre National de la Recherche Scientifique, the French Ministery of Higher Education and Research, the Région Lorraine, the Fonds Européen de Développement Régional, and the European Research Council under the European Community's Seventh Framework Programme (FP7/2007-2013 grant agreements no. 226846 to M.C. and no. 267255 to B.M.). We particularly thank ]. D. Allton for excellent sample curation and C. Olinger for ion trajectory calculations. The SiC standard was provided by A. Kallio. This work benefitted from discussions with the members of the Genesis Science Team, in particular, R. O. Pepin, R. Wieler, and A. N. Davies. Comments on the draft by V. S. Heber, K. McKeegan, P. Bochsler, and three reviewers were appreciated. The full data set is available as supporting online material (SOM).

\section{Supporting Online Material}

www.sciencemag.org/cgi/content/full/332/6037/1533/DC1 Materials and Methods

Figs. S1 to S12

Reference (54)

22 February 2011; accepted 26 April 2011 10.1126/science. 1204656 